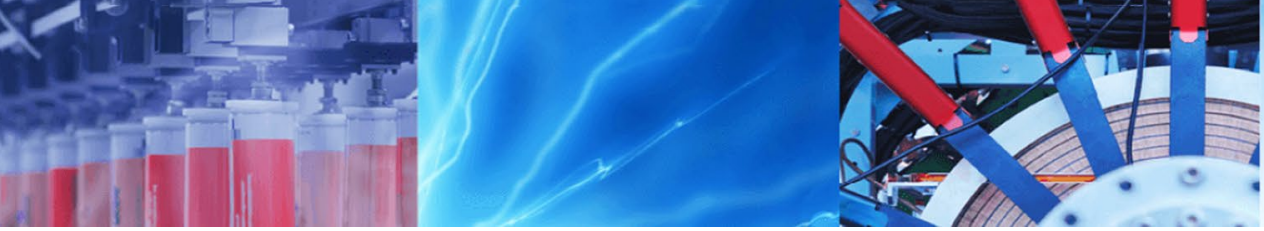

Research Article

\title{
Design of terahertz spectroscopy based optical sensor for chemical detection
}

\author{
Shuvo Sen ${ }^{1} \cdot$ Kawsar Ahmed ${ }^{1,2}$ (1)
}

(c) Springer Nature Switzerland AG 2019

\begin{abstract}
In this article, a new design of circular cladding with a rotated-hexacore in photonic crystal fiber (RH-CPCF) has been suggested for chemical sensing application in the $\mathrm{THz}$ regime. The five layers circular cladding and two layers rotatedhexacore in circular shape are designed here. All numerical results are obtained with a procedure of finite element method and perfectly match layered boundary condition in terahertz $(\mathrm{THz})$ wave propagation. After the simulation result, the proposed RH-CPCF shows the high relative sensitivity is $76.44 \%, 77.16 \%$ and $73.20 \%$ for three chemicals such as Ethanol $(n=1.354)$, Benzene $(n=1.366)$ and Water $(n=1.330)$ at $1 \mathrm{THz}$. On the other hand, the low confinement losses are $2.33 \times 10^{-03} \mathrm{~dB} / \mathrm{m}, 3.07 \times 10^{-06} \mathrm{~dB} / \mathrm{m}$ and $2.84 \times 10^{-02} \mathrm{~dB} / \mathrm{m}$ for same in three chemicals at $1 \mathrm{THz}$. Moreover, effective area, effective mode index and total power fraction in core air holes are also briefly described here. In addition, this proposed circular photonic crystal fiber (RH-CPCF) can be used especially for chemical sensing in biomedical, industrial quality control, material research, micro-optics and many communication applications in $\mathrm{THz}$ technology.
\end{abstract}

Keywords Terahertz sensor - Optical sensor · FEM based analysis · Sensitivity · Photonic crystal fiber · Optical loss profile

\section{Introduction}

Many communication areas and biological department are used to terahertz $(\mathrm{THz})$ wave in the recent years properly. On the other hand, there are many sectors such as sensor [1], spectroscopy [2-4], polarization [5], defense [6] and astronomy [7] etc. are also used to $\mathrm{THz}$ frequency. The range from 0.1 to 10 are called THz band in the frequency regime. This terahertz band related PCF sensor has become a more suitable for different types of cancer applications in biomedical sectors [8,9]. Moreover, terahertz spectrum is more perfect than $\mathrm{X}$-ray because it has no harmful radiation.

There are three primary elements such as source [10], waveguide [11] and detector [12] of a full THz system. The source and detector element are developing day by day in present years. Moreover, terahertz wave technology and sensing method are huge updated. As a result, this $\mathrm{THz}$ band technology is used to transmit terahertz waves to achieve better sensing with strong flexibility and easily for the long distance communication system. Now-a-days, many researchers have been reported a large number of $\mathrm{THz}$ waveguides such as Dielectric sub-wavelength waveguide [13], Bragg fibers [14] and metallic wires [15] etc. But, most of the waveguides are not capable to achieve better desired sensing in a transmission medium. To solve the problem of $\mathrm{THz}$ waveguides, hollow-core and polymer porous are perfect as a new generation photonic crystal fiber (PCF). Besides, many background materials such as Zeonor, Topas, and Teflon etc. are used to compute high relative sensitivity, low confinement loss and other excellent guiding properties properly [16].

Kawsar Ahmed, kawsar.ict@mbstu.ac.bd; k.ahmed.bd@ieee.org; kawsarit08050@mbstu.ac.bd; Shuvo Sen, shuvombstu.it12009@ gmail.com | 'Department of Information and Communication Technology (ICT), Mawlana Bhashani Science and Technology University (MBSTU), Santosh, Tangail 1902, Bangladesh. ${ }^{2}$ Group of Bio-photomati $\chi$, Mawlana Bhashani Science and Technology University (MBSTU), Santosh, Tangail 1902, Bangladesh. 
THz band based PCFs are descried by many researchers to calculate successfully the guiding properties as like as relative sensitivity, confinement loss, effective area, effective mode index, total power fraction, highly birefringence and ultra-flat dispersion [17] etc. The researchers Ademgil et al. [18] were reported PC-PCF structure for chemical sensor in 2015. This proposed PC-PCF structure provides lower sensitivity $23.75 \%$ and higher confinement loss in optical wavelength. Arif et al. [19] recommended a hexagonal micro structured PCF to obtain the sensitivity is $59 \%$ and loss of $10^{-11} \mathrm{~dB} / \mathrm{m}$ for liquid sensing applications in 2016. The hybrid PCF (H-PCF) were proposed by Asaduzzaman et al. [20] to calculate the sensitivity of $49.17 \%$ and leakage loss of $2.75 \times 10^{-10} \mathrm{~dB} / \mathrm{m}$. The folded cladding based PCF were reported by Ahmed et al. [21] to compute the sensitivity of $65.18 \%$ and loss of $2.07 \times 10^{-5} \mathrm{~dB} / \mathrm{m}$ for liquid sensor in 2017. As a result, we have seen that the background material is used by silica in their proposed articles [18-21] to gained sensitivity, confinement loss and other guiding properties in optical wavelength. Moreover, we see that the achievement of sensitivity and the loss are not up to the mark after investigating the computed results of articles [18-21]. So, we found a new opportunity to develop our proposed terahertz based PCF sensor to achieve mainly high relative sensitivity and low confinement loss in the $\mathrm{THz}$ wave technology.

This article has proposed THz based RH-CPCF sensor where core is in a roated-hexa manner. The recommended $\mathrm{RH}-\mathrm{CPCF}$ sensor has two rings roated-hexacore and five rings circular cladding. Zeonor is used as the background material of the reported $\mathrm{RH}-\mathrm{CPCF}$ sensor. To compare with recent published articles [22-34], the proposed $\mathrm{RH}-\mathrm{CPCF}$ shows the better performance of sensitivity and confinement loss are $76.44 \%, 77.16 \%, 73.20 \%$ and $2.33 \times 10^{-03} \mathrm{~dB} / \mathrm{m}, 3.07 \times 10^{-06} \mathrm{~dB} / \mathrm{m}, 2.84 \times 10^{-02} \mathrm{~dB} / \mathrm{m}$ for ethanol, benzene and water respectively at $1 \mathrm{THz}$ frequency. So, this suggested RH-CPCF is highly useful in biomedicine and industrial chemicals research for sensing applications in the terahertz frequency range.

\section{Design methodology}

Figure 1 indicates the proposed views of RH-CPCF with a 5-layer cladding area and 2-layer roated-hexacore area. The number of first layer air holes is eight. 16, 32, 64, and 128 air holes are second, third, fourth, and fifth layer respectively in the cladding region. The distance of hole to hole within two or same rings is defined by pitch. The parameters $\Lambda_{1}$ and $d_{1}$ are indicated by pitch and diameter in the cladding area. On the other hand, the roated-hexa shape is defined as a core area that the first layer of six air holes contain a $20^{\circ}, 80^{\circ}, 140^{\circ}, 200^{\circ}, 260^{\circ}, 320^{\circ}$ angles

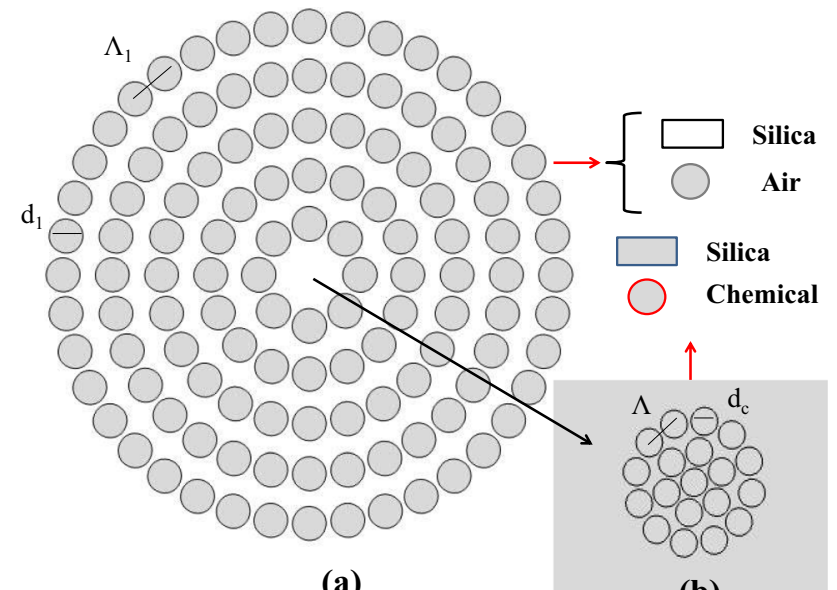

(a)

(b)

Fig. 1 The proposed views of RH-CPCF optical fiber with cladding region and core region

and the second layer of 12 circular air holes contain a $20^{\circ}$, $50^{\circ}, 80^{\circ}, 110^{\circ}, 140^{\circ}, 170^{\circ}, 200^{\circ}, 230^{\circ}, 260^{\circ}, 290^{\circ}, 320^{\circ}, 350^{\circ}$ angles. The pitch and diameter are indicated by $\Lambda$ and $d_{c}$ in the core area. The core region is loaded up with three chemicals such as Ethanol $(n=1.354)$, Benzene $(n=1.366)$ and Water $(n=1.330)$. The background material such as a Zeonor is used in this proposed RH-CPCF sensor. The air filling ratio is defined by $d_{1} / \Lambda_{1}$ in the cladding area. Moreover, this ratio can protect between the two air holes distance in the cladding region.

\section{Numerical analysis}

We know that THz PCF based sensor perfectly depends upon the intensity of light matter interaction by using Beer-Lambert law,

$\mathrm{I}(f)=I_{0}(f) \exp \left[-r \alpha_{m} I_{c}\right]$

where the intensity of lights of the analytes is I(f) which already to be passed, and the light before passing through the analytes is $I_{0}(f)$, absorption coefficient is $a_{m}$, length of channel is $I_{c}$ and the leading frequency of the fiber is $f$, and relative sensitivity mood is $r$.

The absorbance $(A)$ interprets the intensity of the incident $I$ and the transmitted $I_{0}$ light of the analytes and this can be written as,

$A=\log \left(\frac{I}{I_{o}}\right)=-r \alpha_{m} I_{c}$

To compute of the sensitivity of PCF-THz sensors we need to know the rule of relative sensitivity. So, the relative sensitivity is defined by $\mathrm{R}$, 
$\mathrm{R}=\frac{n_{r}}{n_{\text {eff }}} \times E$

where the refractive index is $n_{r^{\prime}}$ effective mode index is $n_{\text {eff }}$ and the total sum of light matter interaction is $E$, that can be expressed as,

$E=\frac{\int_{\text {sample }} R_{e}\left(E_{x} H_{y}-E_{y} H_{x}\right) d x d y}{\int_{\text {total }} R_{e}\left(E_{x} H_{y}-E_{y} H_{x}\right) d x d y} \times 100 \%$

where the electric field of $x, y$ component are $E_{x}$ and $E_{y^{\prime}}$ and $\mathrm{H}_{\mathrm{x}}$ and $\mathrm{H}_{\mathrm{y}}$ are mentioned as the magnetic field of $\mathrm{x}, \mathrm{y}$ components.

Confinement loss is another important guiding property of any PCF. So, we know that the confinement or leakage loss $L_{c}$ is calculated by,

$\mathrm{L}_{\mathrm{c}}=8.686 \times \mathrm{K}_{0} \operatorname{Im}\left[\mathrm{n}_{\text {eff }}\right](\mathrm{dB} / \mathrm{m})$

where $K_{0}=2 \pi / \lambda ; \lambda$ is the wavelength of light and $I_{m}\left(n_{\text {eff }}\right)$ indicates an effective refractive index as an imaginary part.

We know that the main part is designing in effective mode area in PCF. This largely depends on the wavelength as well as the core area. So, the effective area can be expressed by

$A_{\text {eff }}=\frac{\left[\int I(r) r d r\right]^{2}}{\left[\int I^{2}(r) d r\right]^{2}}$

Here, cross sectional electric field intensity is $I(r)=\left|E_{t}\right|^{2}$ and effective mode area is $A_{\text {eff }}$

Power fraction helps to observe how much power or energy is moving in the variety of areas. So, $\eta$ is determined by

$\eta=\frac{\int_{\mathrm{i}} S_{z} d A}{\int_{\text {all }} S_{z} d A}$

Here, the region of interest is indicated by nominator integration (cladding, core, air hole etc.). On the other hand, the denominator integration defines in the entire cross-section area.

\section{Numerical results and discussion}

We know that finite element method (FEM) is mostly useful to compute the guiding properties the proposed $\mathrm{RH}$ CPCF. COMSOL Multiphysics 4.2 versions software tool is also used to calculate all numerical results in the frequency range from 0.8 to $3 \mathrm{THz}$.

Figure 2 shows (a) x-polarization and (b) y-polarization optical mode field distribution for $1 \mathrm{THz}$. The light

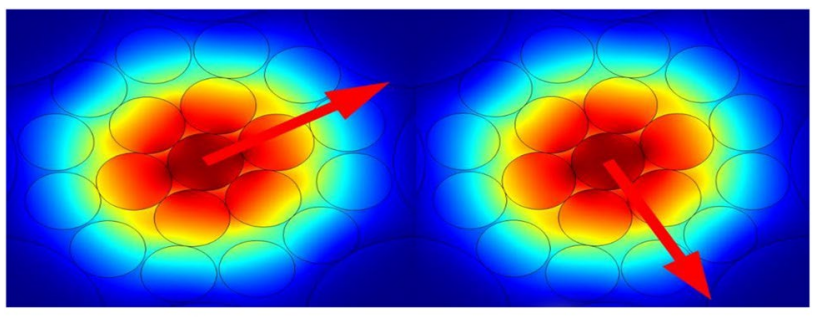

(a)

(b)

Fig. 2 a x-polarization and $\mathbf{b}$ y-polarization mode at $1 \mathrm{THz}$

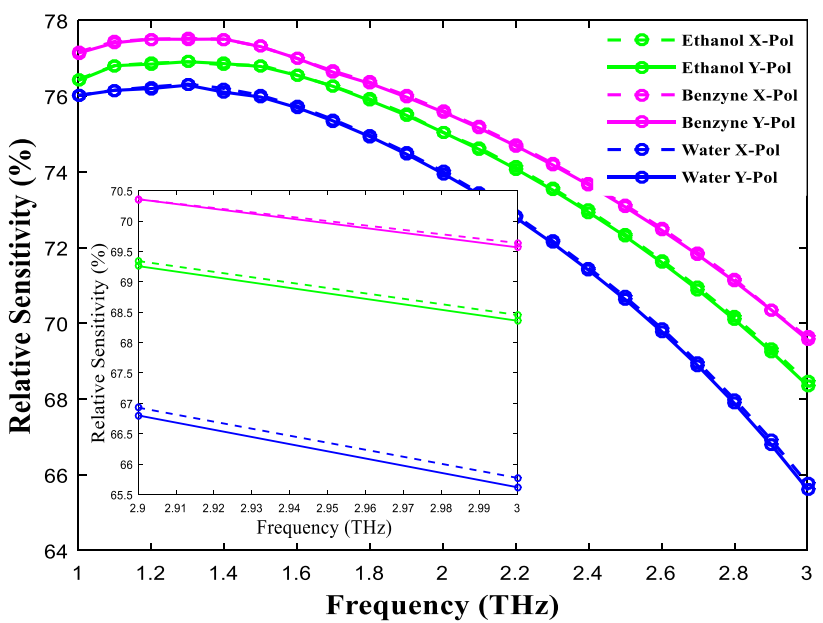

Fig. 3 Relative sensitivity versus of frequency for optimum parameters of the proposed $\mathrm{RH}-\mathrm{CPCF}$

confinement is increased highly at the area in core which increases the sensitivity both $\mathrm{x}$-polarization and $y$-polarization of the proposed $\mathrm{RH}-\mathrm{CPCF}$. It is known that different intensity of light are passed through the fiber for different polarizations. As a result, leakage loss, sensitivity and other parameters response of the fiber are varied in large amount. But in this structure, quite same amount of light pass through the core for both polarizations. So there are small amount of variations of the investigated parameters those are shown in the Figs. 3, 4, 5, 6, 7, 8, 9, 10 and 11 respectively.

Figure 3 indicates that the relative sensitivity versus of frequency for both $\mathrm{x}$ and $\mathrm{y}$ mode with optimum structure parameters. The curve of relative sensitivity is going to downwards with the expansion of frequency and afterward diminishes bit by bit of frequency range. It's also to be seen that the relative sensitivity of ethanol, benzene and water reaches top at $1.6 \mathrm{THz}$ and then started to diminish at $3 \mathrm{THz}$. The highest relative sensitivity of proposed $\mathrm{RH}-\mathrm{CPCF}$ is $73.20 \%, 76.44 \%, 77.16 \%$ for Water $(n=1.330)$, Ethanol $(n=1.354)$ and Benzene $(n=1.366)$, respectively, at $1 \mathrm{THz}$. Finally to propose the structure, it 


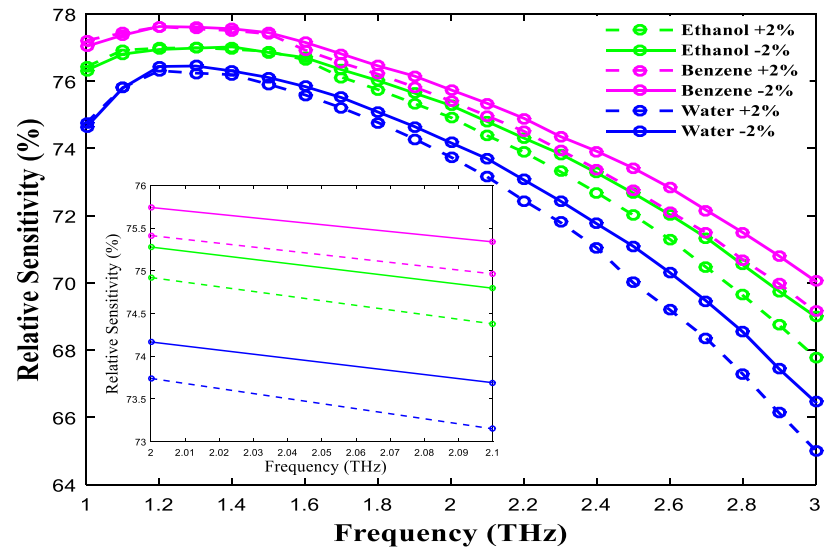

Fig. 4 Relative sensitivity versus of frequency for $2 \%$ more or less then optimum parameters of the proposed RH-CPCF

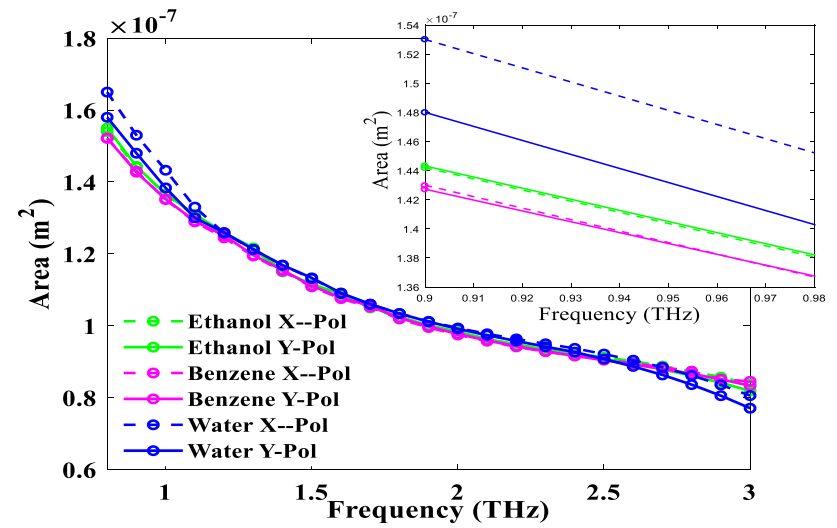

Fig. 5 Effective area versus of frequency for optimum design parameters of the proposed $\mathrm{RH}-\mathrm{CPCF}$

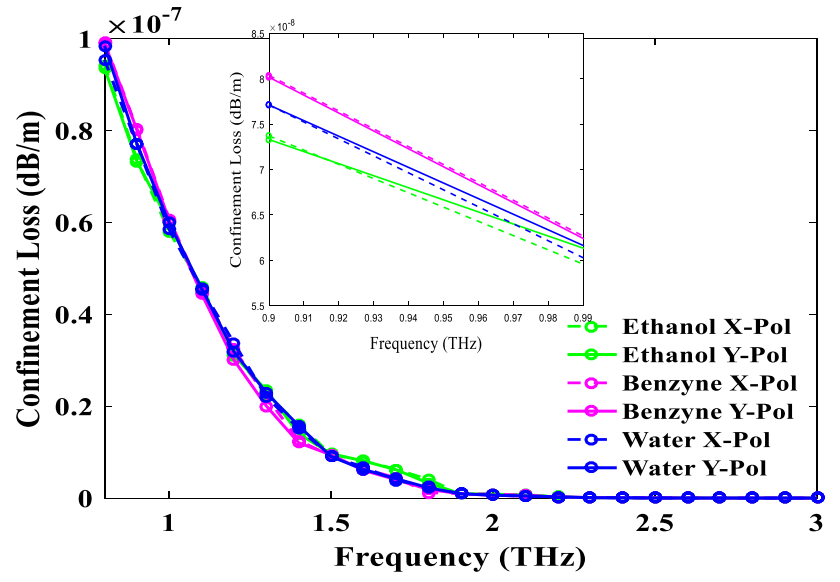

Fig. 6 Confinement loss versus of frequency for optimum design parameters of the proposed $\mathrm{RH}-\mathrm{CPCF}$

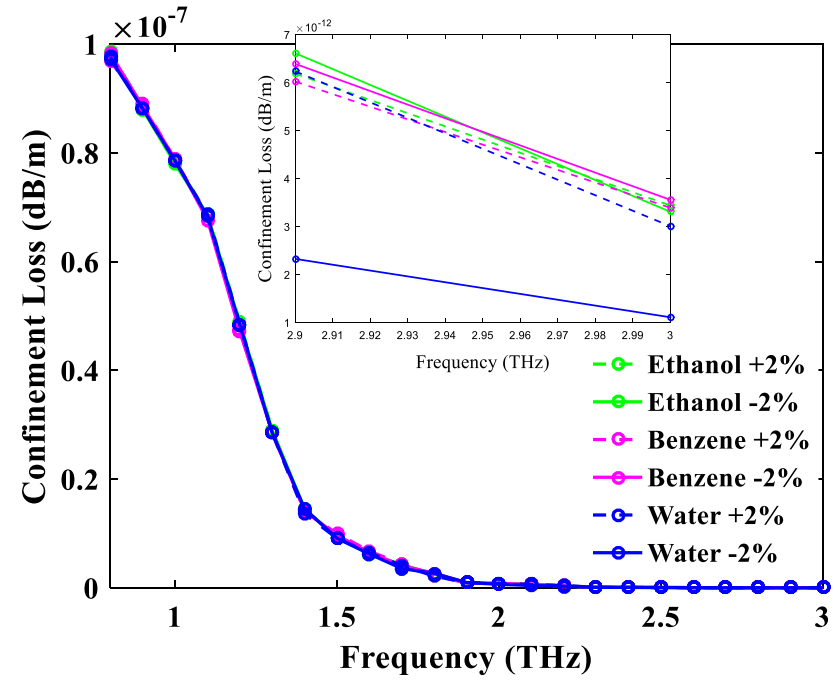

Fig. 7 Confinement loss versus of frequency for $2 \%$ more or less then optimum parameters of the proposed $\mathrm{RH}-\mathrm{CPCF}$

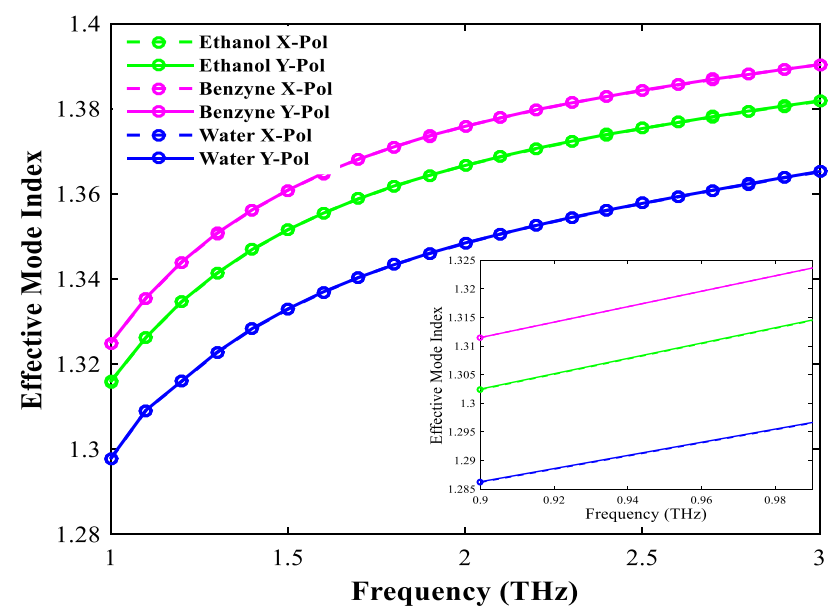

Fig. 8 Effective mode index versus of frequency for optimum design parameters of the proposed $\mathrm{RH}-\mathrm{CPCF}$

is tuned to achieve maximum sensitivity. Then, we have corrected all optimum parameters elaborately here. The optimum parameters are cladding diameter $d_{1}=254 \mu \mathrm{m}$, cladding diameter $\mathrm{d}_{2}=\mathrm{d}_{3}=\mathrm{d}_{4}=\mathrm{d}_{5}=249.60 \mu \mathrm{m}$, cladding pitch $\Lambda_{1}=320 \mu \mathrm{m}$, cladding pitch $\Lambda_{2}=\Lambda_{3}=\Lambda_{4}=\Lambda_{5}=332$ $\mu \mathrm{m}$, core diameter $\mathrm{d}_{\mathrm{c}}=82.40 \mu \mathrm{m}$ and core pitch $\Lambda=82.45$ $\mu \mathrm{m}$.

Figure 4 demonstrates the relative sensitivity by changing the core and cladding air-hole parameters of $\pm 2 \%$ with optimum values for the proposed $\mathrm{RH}-\mathrm{CPCF}$. By the variation of the core and cladding air-hole parameters of $\pm 2 \%$, it is clearly visualized that we get higher sensitivity marginally than the optimum value. It's also to be seen that relative sensitivity of ethanol, benzene and water reaches at $1.6 \mathrm{THz}$ and then started to diminish at $3 \mathrm{THz}$.

\section{SN Applied Sciences}




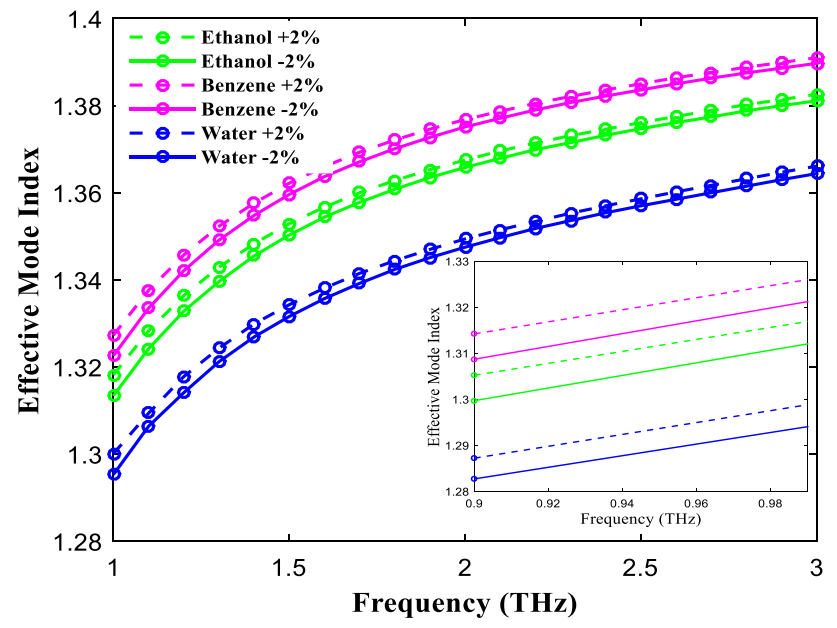

Fig. 9 Effective mode index versus of frequency for $2 \%$ more or less then optimum parameters of the proposed $\mathrm{RH}-\mathrm{CPCF}$

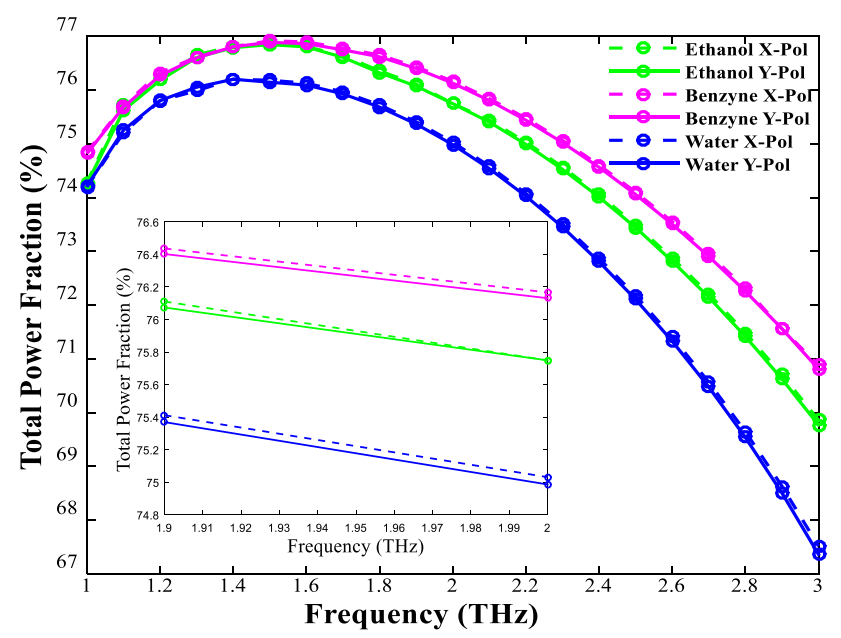

Fig. 10 Total power fraction versus of frequency for optimum parameters of the proposed $\mathrm{RH}-\mathrm{CPCF}$

The relative sensitivity and confinement loss at y polarization mode for benzene, ethanol and water are $77.21 \%$, $76.43 \%, 72.76 \%$ and $1.39 \times 10^{-7} \mathrm{~dB} / \mathrm{m}, 1.43 \times 10^{-7} \mathrm{~dB} / \mathrm{m}$, and $1.49 \times 10^{-7} \mathrm{~dB} / \mathrm{m}$ for $1 \mathrm{THz}$ respectively. In addition, the parameters are cladding diameter $\mathrm{d}_{1}=259.08 \mu \mathrm{m}$, cladding diameter $d_{2}=d_{3}=d_{4}=d_{5}=254.592 \mu \mathrm{m}$, cladding pitch $\Lambda_{1}=326.4 \mu \mathrm{m}$, cladding pitch $\Lambda_{2}=\Lambda_{3}=\Lambda_{4}=\Lambda_{5}=338.64 \mu \mathrm{m}$, core diameter $d_{c}=80.752 \mu \mathrm{m}$ and core pitch $\Lambda=84.801 \mu \mathrm{m}$.

Figure 5 shows the effective area versus of frequency of the proposed $\mathrm{RH}-\mathrm{CPCF}$ for optimum values. This plot indicates that the effective area of the proposed RH-CPCF diminishes when the frequency is increased. The effective area for ethanol, benzene and water is $1.36 \times 10^{-7} \mathrm{~m}^{2}$, $1.35 \times 10^{-7} \mathrm{~m}^{2}$ and $1.43 \times 10^{-7} \mathrm{~m}^{2}$, respectively, for $1 \mathrm{THz}$.

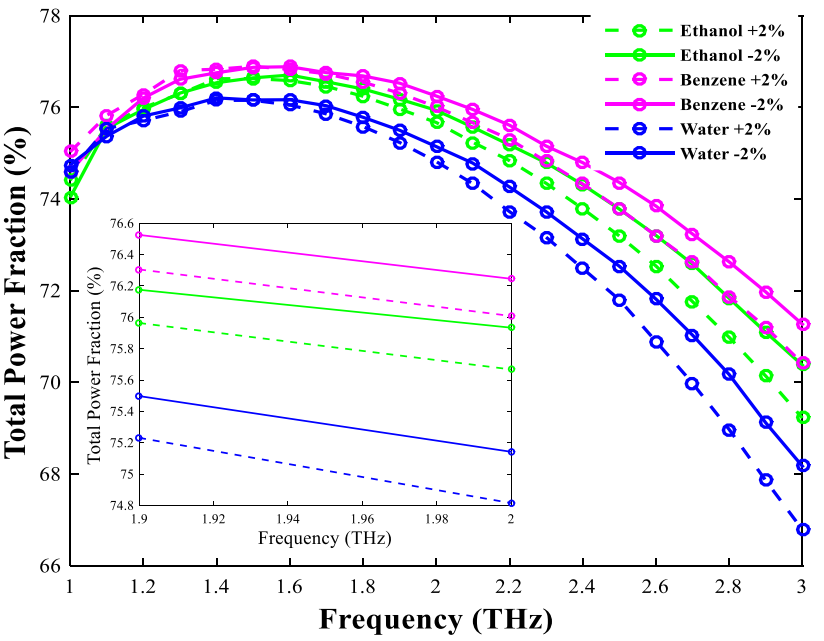

Fig. 11 Total power fraction versus of frequency for $2 \%$ more or less then optimum design parameters of the proposed $\mathrm{RH}-\mathrm{CPCF}$

The feature of confinement loss versus of frequency at optimum parameters is appeared in Fig. 6 . It is indicated that the confinement loss is being reduced with the expansion of frequency. It is also seen that a certain frequency of $2.1 \mathrm{THz}$ confinement loss is remain constant. The confinement losses are $2.84 \times 10^{-02} \mathrm{~dB} / \mathrm{m}, 2.33 \times 10^{-03} \mathrm{~dB} / \mathrm{m}$, and $3.07 \times 10^{-06} \mathrm{~dB} / \mathrm{m}$ for three chemicals such as Water $(n=1.330)$, Ethanol $(n=1.354)$ and Benzene $(n=1.366)$, respectively, at $1 \mathrm{THz}$. Here, the optimum parameters are cladding diameter $\mathrm{d}_{1}=254 \mu \mathrm{m}$, cladding diameter $\mathrm{d}_{2}=\mathrm{d}_{3}=\mathrm{d}_{4}=\mathrm{d}_{5}=249.60 \mu \mathrm{m}$, cladding pitch $\Lambda_{1}=320 \mu \mathrm{m}$, cladding pitch $\Lambda_{2}=\Lambda_{3}=\Lambda_{4}=\Lambda_{5}=332 \mu \mathrm{m}$, core diameter $\mathrm{d}_{\mathrm{c}}=82.40 \mu \mathrm{m}$ and core pitch $\Lambda=82.45 \mu \mathrm{m}$.

Figure 7 indicates the confinement loss versus of frequency for $\pm 2 \%$ by changing the optimum values in the proposed RH-CPCF. It is also noted that the expansion of frequency according to the confinement loss is being reduced. It is also seen that a certain frequency of $2.1 \mathrm{THz}$, the confinement loss is remain constant. $1.39 \times 10^{-7} \mathrm{~dB} / \mathrm{m}$, $1.43 \times 10^{-7} \mathrm{~dB} / \mathrm{m}$, and $1.49 \times 10^{-7} \mathrm{~dB} / \mathrm{m}$ are correspondingly confinement loss for three chemicals such as water, ethanol and benzene at $1 \mathrm{THz}$. Here, we can clearly see from the comparison of Figs. 6 and 7 results that the confinement loss versus of frequency shows the negligible change.

Figure 8 indicates the effective mode index versus of frequency for both $x$ and $y$ mode in optimum parameters. It is seen that the effective mode index is being increased with the expansion of frequency. It is also seen that the effective mode index range is started with 1.27 and the frequency started with $0.5 \mathrm{THz}$. It is noted that effective mode indices can reach the top value 1.39 with the expansion of frequency in $\mathrm{THz}$ waves. 
Figure 9 shows the effective mode index versus of frequency for $\pm 2 \%$ changing of the optimum values. It is also indicated that the expansion of frequency according to the effective mode index is being increased. It is also observed that the effective mode index range is started with 1.27 and the frequency started with $0.5 \mathrm{THz}$. It is also seen that effective mode indices can reach the higher value 1.39 with the expansion of frequency. Now, from the comparison of the effective mode index versus of frequency in Figs. 8 and 9, it is seen that the feature of effective mode index versus of frequency show almost same response in range of $\mathrm{THz}$ frequency.

In Fig. 10, it indicates the total power fraction versus of frequency for both $\mathrm{x}$ and $\mathrm{y}$ polarization in the proposed $\mathrm{RH}-\mathrm{CPCF}$. It is seen that the total power fraction increases with the increment of frequency. Moreover, it is observed that the frequency beginning from $0.5 \mathrm{THz}$, achieves a top position at $1.5 \mathrm{THz}$ and then started to diminish.

In Fig. 11, it shows the total power fraction versus of frequency for $\pm 2 \%$ by changing the optimum values. It is also indicated that total power fraction is increases according to the increment of frequency. It is also seen that the frequency beginning from $0.5 \mathrm{THz}$, achieves a most extreme position at $1.5 \mathrm{THz}$ and then started to diminish.

Here, after completing all numerical results from Figs. 10 and 11 , it is also seen that the feature of the total power fraction versus of frequency is no major change in terahertz frequency range.

We have also computed the $\pm 2 \%$ parameters with changing optimum parameters of the proposed RH-CPCF sensor. As a result, the optimum parameters are varied with changing $\pm 2 \%$ parameters of relative sensitivity and confinement loss. From Table 1, it is clearly visualized that there are no major change of the sensitivity response and confinement loss response due to the variation of optimum parameters up to $\pm 2 \%$. So we can say that after fabrication process, the proposed optical sensor will be provided same responses.

The suggested RH-CPCF shows highly relative sensitivity and low confinement loss than other prior PCFs for ethanol $(n=1.354)$ which is shown in Table 2. The proposed optical sensor exhibits better optical parameters responses compare to recent published articles.

We know that the fabrication technique is a fundamental issue in any optical fiber. Now-a-days, the sol-gel [35] technique is more popular to fabricate the PCFs in any shape. Moreover, this technique provides freedom to design the structure of cladding and core area in any shapes. So, this sol-gel technique will be useful to fabricate of the proposed RH-CPCF. In recent years, selectively filling technique [36] is a very useful to fill in chemicals into the holes of the core region of any PCF structure and are now routinely used in the laboratory-environment. In this technique, when the holes of the core area are selectively filled with liquids or chemicals, the incident light propagates through the liquids or chemicals directly by either photonic bandgap guidance or effective index guidance. So, we can say that by combining the advantages of the photonic bandgap guidance or effective index-guiding process and the selective filling technique, any photonic crystal fiber whose holes of the core area is filled with liquids or chemicals can provide a better guiding properties practically.

\section{Conclusion}

A novel design of RH-CPCF is structured and investigated for the chemical detection in terahertz region. Zeonor is used as the background material of this proposed terahertz RH-CPCF. The perfectly match layered (PML) and FEM method are used to determine all numerical results
Table 1 The compare table among the change in $\pm 2 \%$ parameters and optimum parameters at $1 \mathrm{THz}$

\begin{tabular}{|c|c|c|c|c|c|c|}
\hline \multirow[t]{2}{*}{ Parameters (\%) } & \multicolumn{3}{|c|}{ Relative sensitivity (\%) } & \multicolumn{3}{|c|}{ Confinement loss $(\mathrm{dB} / \mathrm{m})$} \\
\hline & Water & Ethanol & Benzene & Water & Ethanol & Benzene \\
\hline$+2 \%$ & 73.76 & 76.50 & 77.22 & $4.75 \times 10^{-03}$ & $5.53 \times 10^{-03}$ & $2.27 \times 10^{-06}$ \\
\hline Optimum & 73.20 & 76.44 & 77.16 & 2. $84 \times 10^{-02}$ & $2.33 \times 10^{-03}$ & $3.07 \times 10^{-06}$ \\
\hline$-2 \%$ & 72.64 & 76.32 & 77.04 & $3.65 \times 10^{-01}$ & $1.42 \times 10^{-03}$ & $4.38 \times 10^{-06}$ \\
\hline
\end{tabular}

Table 2 The compare table in design of structure and numerical results among prior PCFs and proposed RH-CPCF at $\mathrm{n}=1.354$

\begin{tabular}{|c|c|c|c|c|c|}
\hline \multirow[t]{2}{*}{ Prior in PCFs } & \multirow[t]{2}{*}{ Sensitivity (\%) } & \multirow{2}{*}{$\begin{array}{l}\text { Confinement } \\
\text { loss }(\mathrm{dB} / \mathrm{m})\end{array}$} & \multirow{2}{*}{$\begin{array}{l}\text { Ring of } \\
\text { number }\end{array}$} & \multicolumn{2}{|l|}{ Design of structure } \\
\hline & & & & Core & Cladding \\
\hline $\mathrm{PCF}_{1}[22]$ & 49.17 & $2.75 \times 10^{-10}$ & 3 & Elliptical holes & Circular \\
\hline $\mathrm{PCF}_{2}[28]$ & 57.18 & $1.11 \times 10^{-11}$ & 5 & Elliptical holes in porous & Hexagonal \\
\hline $\mathrm{PCF}_{3}[33]$ & 61.45 & $1.41 \times 10^{-10}$ & 5 & Porous & Porous \\
\hline Pro. PCF & 76.44 & $2.33 \times 10^{-03}$ & 5 & Roated-hexa & Circular \\
\hline
\end{tabular}


properly. Different polarization modes are analyzed to investigate the different optical parameters. As a result, the relative sensitivity and confinement loss of proposed $\mathrm{RH}$ CPCF are $73.20 \%, 76.44 \%, 77.16 \%$ and $2.33 \times 10^{-03} \mathrm{~dB} / \mathrm{m}$, $3.07 \times 10^{-06} \mathrm{~dB} / \mathrm{m}, 2.84 \times 10^{-02} \mathrm{~dB} / \mathrm{m}$ at three chemicals such as Water $(n=1.330)$, Ethanol $(n=1.354)$ and Benzene $(n=1.366)$ for $1 \mathrm{THz}$. So, we can say clearly that the reported $\mathrm{RH}-\mathrm{CPCF}$ sensor can be used specially for chemical sensing in various biomedical or industrial sectors.

\section{Compliance with ethical standards}

Conflict of interest The authors declare that they have no conflict of interest.

\section{References}

1. Awad MM, Cheville RA (2005) Transmission terahertz wave guide-based imaging below the diffraction limit. Appl Phys Lett 86(22):221107. https://doi.org/10.1063/1.1942637

2. Zhang JQ, Grischkowsky D (2004) Waveguide terahertz timedomain spectroscopy of nanometer water layers. Opt Lett 29(14):617-619. https://doi.org/10.1364/OL.29.00161

3. Islam R, Habib MS, Hasanuzzaman GK, Rana S, Sadath MA, Markos C (2016) A novel low-loss diamond-core porous fiber for polarization maintaining terahertz transmission. IEEE Photonic Technol Lett 28(14):1537-1540. https://doi.org/10.1109/ LPT.2016.2550205

4. Cook DJ, Decker BK, Allen MG (2005) Quantitative THz spectroscopy of explosive materials. In: OSA conference USA, PSISR-1196. https://doi.org/10.1364/OTST.2005.MA6

5. Ho L, Pepper M, Taday P (2008) Terahertz spectroscopy: signatures and fingerprints. Nat Photonics 2(9):541. https://doi. org/10.1038/nphoton.2008.174

6. Fukunaga K, Sekine N, Hosako I, Oda N, Yoneyama H, Sudou T (2008) Realtime terahertz imaging for art conservation science. J Eur Opt Soc Rapid Publ 3:08027. https://doi.org/10.2971/ jeos.2008.08027

7. Kawase K, Ogawa Y, Watanabe $Y$, Inoue H (2003) Non-destructive terahertz imaging of illicit drugs using spectral fingerprints. Opt Express 11(20):2549-2554. https://doi.org/10.1364/OE.11.00254 9

8. Markelz AG, Roitberg AE, Heilweil J (2000) Pulsed terahertz spectroscopy of DNA, bovine serum albumin and collagen between 0.1 and $2.0 \mathrm{THz}$. Chem Phys Lett 320(1):42-48. https ://doi.org/10.1016/S0009-2614(00)00227-X

9. https://www.umass.edu/cphm/content/real-time-breast-cance r-celldetection-terahertz. Accessed 26 May 2019

10. Islam R, Rana S (2015) Dispersion flattened, low-loss porous fiber for single-mode terahertz wave guidance. Opt Eng 54(5):055102. https://doi.org/10.1117/1.OE.54.5.055102

11. Ren NF, Chen MY, Sun B, Ge L (2013) Design of subwavelength optical fibre for low-loss Terahertz transmission. J Euro Opt Soc Rapid Publ 8:13068. https://doi.org/10.2971/jeos.2013.13068

12. Kaijage SF, Ouyang Z, Jin X (2013) Porous core photonic crystal fiber for low loss terahertz wave guiding. IEEE Photonics Technol Lett 25(15):1454-1457. https://doi.org/10.1109/LPT.2013.22664 12

13. Bowden B, Harrington JA, Mitrofanov O (2007) Silver/polystyrene coated hollow glass waveguides for the transmission of terahertz radiation. Opt Lett 32:2945-2947. https://doi. org/10.1364/OL.32.002945

14. Lai CH, Hsueh YC, Chen HW, Huang YJ, Chang HC, Sun CK (2009) Low-index terahertz pipe waveguides. Opt Lett 34:3457-3459. https://doi.org/10.1364/OL.34.003457

15. Ali S, Aljunid S, Ahmad B, Ahmed N (2016) Ultra-flat low material loss porous core $\mathrm{THz}$ waveguide with near zero flat dispersion. Electron Lett 52:863-865. https://doi.org/10.1049/ el.2016.0364

16. Ahmed K, Chowdhury S, Paul BK, Islam MS, Sen S, Islam MI, Asaduzzaman S (2017) Ultrahigh birefringence, ultralow material loss porous core single-mode fiber for terahertz wave guidance. Appl Opt 56(12):3477-3483. https://doi.org/10.1364/ AO.56.003477

17. Ademgil H (2014) Highly sensitive octagonal photonic crystal fiber-based sensor. Optik-Int J Light Electron Opt 125(20):62746278. https://doi.org/10.1016/j.ijleo.2014.08.018

18. Ademgil $\mathrm{H}$, Haxha S (2015) PCF based sensor with high sensitivity, high birefringence and low confinement losses for liquid analyte sensing applications. Sensors 15(12):31833-31842. https://doi.org/10.3390/s151229891

19. Arif MFH, Ahmed K, Asaduzzaman S, Azad MAK (2016) Design and optimization of photonic crystal fiber for liquid sensing applications. Photonic Sens 6(3):279-288. https://doi. org/10.1007/s1332

20. Asaduzzaman S, Ahmed K, Bhuiyan T, Farah T (2016) Hybrid photonic crystal fiber in chemical sensing. Springer Plus 5(1):748. https://doi.org/10.1186/s40064-016-2415-y

21. Paul BK, Ahmed K, Asaduzzaman S, Islam MS (2017) Folded cladding porous shaped photonic crystal fiber with high sensitivity in optical sensing applications: design and analysis. Sens BioSens Res 12:36-42. https://doi.org/10.1016/j.sbsr.2016.11.005

22. Ahmed K, Morshed M (2016) Design and numerical analysis of micro structured-core octagonal photonic crystal fiber for sensing applications. Sens Bio-Sens Res 7:1-6. https://doi. org/10.1016/j.sbsr.2015.10.005

23. Sen S, Islam MS, Paul BK, Islam MI, Chowdhury S, Ahmed K, Hasan MR, Uddin MS, Asaduzzaman S (2017) Ultra-low loss with single mode polymer-based photonic crystal fiber for $\mathrm{THz}$ waveguide. J Opt Commun. https://doi.org/10.1515/joc-2017-0104

24. Ahmed K, Paul BK, Chowdhury S, Sen S, Islam MI, Islam MS, Hasan MR, Asaduzzaman S (2017) Design of a single-mode photonic crystal fibre with ultra-low material loss and large effective mode area in THz regime. IET Opto-electron 11:265-271. https ://doi.org/10.1049/iet-opt.2017.0028

25. Islam MS, Paul BK, Ahmed K, Asaduzzaman S, Islam MI, Chowdhury S, Sen S, Bahar AN (2018) Liquid-infiltrated photonic crystal fiber for sensing purpose: design and analysis. Alex Eng $J$ 57:1459-1466. https://doi.org/10.1016/j.aej.2017.03.015

26. Osório JH, Hayashi JG, Espinel YA, Franco MA, Andrés MV, Cordeiro CM (2014) Photonic-crystal fiber-based pressure sensor for dual environment monitoring. Appl Opt 53:668-3672. https:// doi.org/10.1364/AO.53.003668

27. Amiri IS, Paul BK, Ahmed K, Aly AH, Zakaria R, Yupapin P, Vigneswaran D (2019) Tri-core photonic crystal fiber based refractive index dual sensor for salinity and temperature detection. Microw Opt Technol Lettrs 61(3):847-852. https://doi. org/10.1002/mop.31612

28. Sen S, Chowdhury S, Ahmed K, Asaduzzaman S (2017) Design of a porous cored hexagonal photonic crystal fiber based optical sensor with high relative sensitivity for lower operating wavelength. Photonic Sens 7(1):55-65. https://doi.org/10.1007/s1332 0-016-0384-y

29. Hameed MFO, Obayya SSA, Wiltshire RJ (2009) Multiplexerdemultiplexer based on nematic liquid crystal photonic crystal 
fiber coupler. Opt Quantum Electron 41:315-326. https://doi. org/10.1007/s11082-009-9334-x

30. Dadabayev R, Shabairou N, Zalevsky Z, Malka D (2019) A visible light RGB wavelength demultiplexer based on silicon-nitride multicore PCF. Opt Laser Technol 111:411-416. https://doi. org/10.1016/j.optlastec.2018.10.016

31. Malka D, Katz G (2018) An eight-channel C-band demux based on multicore photonic crystal fiber. Nanomaterials 8:845-854. https://doi.org/10.3390/nano8100845

32. Malka D, Peled A (2017) Power splitting of $1 \times 16$ in multicore photonic crystal fibers. Appl Surf Sci 417:34-39. https://doi. org/10.1016/j.apsusc.2017.02.247

33. Chowdhury S, Sen S, Ahmed K, Asaduzzaman S (2017) Design of highly sensible porous shaped photonic crystal fiber with strong confinement field for optical sensing. Opt-Int J Light Electron Opt 142:541-549. https://doi.org/10.1016/j.ijleo.2017.03.123

34. Hasan MR, Islam MA, Rifat AA (2016) A single mode porous-core square lattice photonic crystal fiber for $\mathrm{THz}$ wave propagation.
J Eur Opt Soc Rapid Publ 12:15. https://doi.org/10.1186/s4147 6-016-0017-5

35. El Hamzaoui H, Ouerdane Y, Bigot L, Bouwmans G, Capoen B, Boukenter A, Girard S, Bouazaoui M (2012) Sol-gel derived ionic copper-doped microstructured optical fiber: a potential selective ultraviolet radiation dosimeter. Opt Express 20(28):2975129760. https://doi.org/10.1364/OE.20.029751

36. Cordeiro CM, Dos Santos EM, Cruz CB, de Matos CJ, Ferreira DS (2006) Lateral access to the holes of photonic crystal fibers-selective filling and sensing applications. Opt Express 14(18):8403-8412. https://doi.org/10.1364/OE.14.008403

Publisher's Note Springer Nature remains neutral with regard to jurisdictional claims in published maps and institutional affiliations. 